\title{
LA COMPLEJIDAD DEL DEBIDO PROCESO COMO DERECHO FUNDAMENTAL Y COMO GARANTÍA PROCESAL
}

\author{
Islas Rodríguez, Alfredo ${ }^{1}$ \\ Camargo Pacheco, María de Jesús ${ }^{2}$
}

\section{Resumen}

El debido proceso es un derecho fundamental, subjetivo y público que contiene a su vez un conjunto de garantías procesales, su cumplimiento garantiza la eficacia del derecho a la tutela jurisdiccional efectiva. Actualmente el debido proceso es considerado como uno de los principales logros del ciudadano, por medio de esta conquista las personas estamos en posibilidad, de exigir de las autoridades el respeto a nuestros derechos fundamentales. En la doctrina jurídica existe una polémica respecto de si el debido proceso legal es un derecho fundamental o una garantía, en este artículo se analizan las opiniones doctrinales que prevalecen al respecto, con el objeto de determinar su contenido y alcance, para lo cual, exponemos los conceptos del debido proceso, derecho fundamental y garantía. En la presente investigación se prefirió utilizar los referentes conceptuales de la teoría jurídica contemporánea, específicamente del garantismo y neoconstitucionalismo.

Palabras clave: Debido proceso, Garantía, Derecho fundamental

\footnotetext{
${ }^{1}$ Maestro investigador de la Unidad Regional Sur, titular de las asignaturas de garantías y amparo, miembro de la Academia de Derecho. Comunicaciones dirigirse a aislasavojoa.uson.mx.

2 Maestra investigadora de la Unidad Regional Sur, titular de las asignaturas de Seminario de Derecho Penal I y II, miembro de la Academia de Derecho. Comunicaciones dirigirse a mcamargo.uson.mx.
} 
http://revistainvestigacionacademicasinfrontera.com

\section{A manera de introducción contextualizacion del problema.}

Uno de los derechos fundamentales de rango constitucional de las personas, que se encuentra íntimamente vinculado con la posibilidad de acceder a la justicia y preservar la libertad es sin duda el debido proceso legal. El debido proceso es un derecho fundamental, subjetivo y público que contiene a su vez un conjunto de garantías procesales. El cumplimiento del debido proceso garantiza la eficacia del derecho a la tutela jurisdiccional efectiva.

Actualmente el debido proceso es considerado como uno de los principales logros del ciudadano, por medio de esta conquista las personas estamos en posibilidad, de exigir de las autoridades el respeto a nuestros derechos fundamentales. El debido proceso como derecho fundamental, es entendido como conjunto de garantías sustantivas y procesales que protegen a las personas sujetas a cualquier proceso, y que les aseguran a lo largo del mismo, una recta y cumplida administración de justicia, la seguridad jurídica y la fundamentación y motivación de las resoluciones que se dicten.

Por lo antes expresado, este artículo se centrará en determinar cuál es el contenido y alcance del debido proceso cómo derecho fundamental.

El objetivo central es analizar en qué consiste el derecho fundamental del debido proceso contenida en el artículo 14 Constitucional y cuáles son sus garantías.

Para estar en condiciones de desarrollar el tema se consultaron una diversidad de fuentes, tanto en los medios electrónicos como documentales. Para la búsqueda de información en los medios electrónicos, fue indispensable identificar 


\section{(Edición especial julio- diciembre 2016)}

http://revistainvestigacionacademicasinfrontera.com
Revista de Investigación

Académica sin Frontera ISSN: 2007-8870

debidamente la base de datos donde se ubicaba el documento, analizar curricularmente al autor, así como revisar cuidadosamente las citas y referencias que se hacían del mismo en otros documentos, con el objeto de tener evidencia de la veracidad de sus conocimientos académicos comparados con otros de sus misma tesitura.

En el desarrollo de este capítulo abordamos a partir de la teoría garantista y neoconstitucionalista, los conceptos de: derechos fundamentales, garantías primarias y secundarias, control de la constitucionalidad, así como, el control de la convencionalidad, buscando contar con herramientas conceptuales con suficiente uniformidad que posibilitaran la comprensión de los cambios que se han realizado en el ámbito de la dogmática constitucional en relación a la protección de los derechos fundamentales de los migrantes en tránsito por México, específicamente del debido proceso, que constituye el núcleo fundamental de la protección jurisdiccional de los derechos.

\section{MARCO CONCEPTUAL}

En este apartado se determina el contenido y esencia de los términos que se consideran esenciales para la comprensión del tema, entre ellos: debido y proceso. En las líneas siguientes se precisa su definición para los efectos de este documento.

Por "debido" que puede entenderse como el procedimiento adecuado para hacer algo, y lo adecuado, es lo que es conforme a un principio; siendo así, debido es, entonces, el proceder de conformidad con uno o varios principios, y así tenemos que el debido proceso es la actividad judicial encaminada a resolver pretensiones, la cual se desarrolla con arreglo y observancia de principios, reunidos en el principio de justicia y particularizados en las normas del procedimiento. 


\section{http://revistainvestigacionacademicasinfrontera.com}

Proceso, en la lengua castellana significa proceder, desenvolvimiento, seguir adelante, es decir, el proceso es un conjunto de operaciones o actos vinculados para lograr un fin, y así el proceso jurisdiccional con los actos del procedimiento tiende a un fin que es resolver un conflicto o contienda mediante una resolución.

En sentido literal y lógico, por proceso se entiende cualquier conjunto de actos coordinados para producir un fin, en el ámbito jurídico, entendemos por proceso una serie de actos coordinados para lograr un fin, y en el caso de proceso judicial, entendemos una serie de actos que realizan las partes y el juez para resolver un conflicto jurídico suscitado entre las primeras, y para que estos actos tengan eficacia jurídica, deben realizarse de acuerdo a los procedimientos preestablecidos y orientados por el contenido sustancial de la Constitución.

Por su parte, el procedimiento es el conjunto de normas de conducta que regulan la actividad, participación, facultades y deberes de los sujetos procesales.

En el nuevo garantismo procesal, los principios del proceso, se definen como normas que ordenan, permiten o prohíben determinadas conductas para la valoración jurídica de la justicia y la dignidad humana, teniendo al ser humano como centro de la sociedad y su convivencia dentro de un Estado de Derecho para la eficacia y desarrollo del debido proceso. Así en este nuevo paradigma, el debido proceso se entiende como un principio jurídico procesal o sustantivo según el cual toda persona tiene derecho a ciertas garantías mínimas, tendientes a asegurar un resultado justo y equitativo dentro de un proceso, y a permitirles a todas las personas tener oportunidad de ser oídas y hacer valer sus pretensiones frente a un juez o una autoridad administrativa.

En cuanto al concepto de garantía, es aquella que tiene por objeto reparar las violaciones que se hayan producido a los principios, valores o disposiciones 


\section{http://revistainvestigacionacademicasinfrontera.com}

Revista de Investigación

Académica sin Frontera

ISSN: 2007-8870

fundamentales. Para Luigi Ferrajoli, las garantías no son iguales que los derechos fundamentales, ya que las garantías son las obligaciones (de hacer o no hacer) que se derivan de los derechos; y que para ello hay garantías positivas y negativas, éstas últimas obligan al Estado y a los particulares a abstenerse de realizar algo para respetar un derecho fundamental, mientras que las positivas generan obligaciones de hacer o actuar para cumplir con la expectativa de algún derecho, tenemos así, que una garantía es el medio para asegurar el cumplimiento de algo, hacerlo eficaz o devolverlo al estado original en caso de que haya sido tergiversado, violado, no respetado.

Tomando como base el principio de legalidad es necesario hacer la distinción entre los derechos y sus garantías, distinción que nos lleva a reconocer que los derechos existen sólo cuando están normativamente establecidos, así como las garantías consistentes en obligaciones y prohibiciones que también deben de estar normativamente establecidas.(Ferrajoli, Los fundamentos de los derechos fundamentales, 2005, pág. 40)

"Garantía" es una expresión del léxico jurídico con la que se designa cualquier técnica normativa de tutela de un derecho subjetivo. El sentido originario del término es, sin embargo, más restringido. Por garantía se entiende, en el lenguaje de los civilistas, un tipo de instituto, derivado del derecho romano, dirigido a asegurar el cumplimiento de las obligaciones y la tutela de los correspondientes derechos patrimoniales. [...] La ampliación del significado del término "garantías" y la introducción del neologismo "garantismo" para referirse a las técnicas de tutela de los derechos fundamentales son, en cambio, relativamente recientes. (Ferrajoli, Garantías, 2007)

Ferrajoli distingue entre garantías positivas y garantías negativas, para él las garantías positivas consisten en la obligación de hacer, mientras que las negativas 


\section{http://revistainvestigacionacademicasinfrontera.com}

en las obligaciones de no hacer, es decir, la prohibición que se desprende "...del comportamiento que es contenido de tal expectativa."

Son, por tanto, garantías, respectivamente positivas y negativas, las obligaciones de prestación y las prohibiciones de lesión correspondientes a esas particulares expectativas que son los derechos subjetivos, sean patrimoniales 0 fundamentales. Pero también son garantías las obligaciones correspondientes a las particulares expectativas de reparación, mediante sanción (para los actos ilícitos) o anulación (para los actos no válidos), que se generan con la violación de los derechos subjetivos. De esta forma, entra en juego una segunda y muy importante distinción. Llamaré garantías primarias o sustanciales a las garantías consistentes en las obligaciones o prohibiciones que corresponden a los derechos subjetivos garantizados. Llamaré garantías secundarias o jurisdiccionales a las obligaciones, por parte de los órganos judiciales, de aplicar la sanción o de declarar la nulidad cuando se constaten, en el primer caso, actos ilícitos y, en el segundo, actos no válidos que violen los derechos subjetivos $\mathrm{y}$, con ellos, sus correspondientes garantías primarias. (Ferrajoli L. , Los fundamentos de los derechos fundamentales, 2005, pág. 41)

Siguiendo a Ferrajoli, al hablar de garantismo nos referiremos al "conjunto de límites y vínculos impuestos a todos los poderes públicos y privados, políticos (o de mayoría) y económicos (o de mercado), en el plano estatal y en el internacional mediante los que se tutelan, a través de su sometimiento a la ley y, en concreto, a los derechos fundamentales en ella establecidos, tanto las esferas privadas frente a los poderes públicos, como las esferas públicas frente a los poderes privados". (Ferrajoli, Garantías) 


\section{http://revistainvestigacionacademicasinfrontera.com}

\section{El debido proceso como derecho fundamental}

De conformidad con la teoría jurídica contemporánea, el debido proceso como derecho fundamental, se entiende como conjunto de garantías que protegen a las personas sometidas a cualquier proceso, y que le aseguran a lo largo del mismo, una recta y cumplida administración de justicia, la seguridad jurídica y la fundamentación de las resoluciones que se dicten. Nos referimos al debido proceso como derecho fundamental y como garantía analizándolo a partir de la teoría jurídica contemporánea, específicamente el neoconstitucionalismo.

El concepto de derecho fundamental, es una de las nociones doctrinales más controvertidas en los últimos tiempos tanto en las Constituciones Europeas como en las Latinoamericanas, pues los derechos fundamentales de conformidad con el criterio de Miguel Carbonell (Carbonell, Los derechos fundamentales en México, 2006, págs. 73-74) interpretando a Luigi Ferrajoli son todos aquellos derechos que están adscritos universalmente a todos en cuanto personas o en cuanto a ciudadanos o personas con capacidad de obrar y que son por lo tanto indisponibles e inalienables. Son derechos fundamentales los que están previstos en la Constitución Política de los Estados, en México la Constitución llama a los derechos ahí contenidos indistintamente garantías individuales o derechos fundamentales.

Entiendo por "derechos fundamentales" en oposición a los "derechos patrimoniales", como la propiedad y el crédito, que son derechos singulares que adquiere cada individuo con exclusión de los demás, aquellos derechos universales $y$, por ello, indisponibles e inalienables, que resultan atribuidos directamente por las normas jurídicas a todos en cuanto personas, ciudadanos o capaces de obrar; ya se trate de derechos negativos, como los derechos de libertad a los que corresponden prohibiciones de lesionar; o de derechos positivos, como los derechos 


\section{http://revistainvestigacionacademicasinfrontera.com}

Revista de Investigación

Académica sin Frontera ISSN: 2007-8870

sociales, a los que corresponden obligaciones de prestación por parte de los poderes públicos.(Ferrajoli, Garantías, 2007)

En este tenor, el debido proceso se encuentra en nuestra Constitución dentro de los derechos fundamentales de seguridad jurídica, los que se definen por la Suprema Corte de Justicia de la Nación, como "aquellos derechos subjetivos públicos a favor de los gobernados que pueden ser oponibles a los órganos estatales, a fin de exigirles que se sujeten a un conjunto de requisitos previos a la comisión de actos que pudieran afectar la esfera jurídica de los individuos, para que éstos no caigan en la indefensión o la incertidumbre jurídica, lo que hace posible la pervivencia de condiciones de igualdad y libertad para todos los sujetos de derechos y obligaciones". (Suprema Corte de Justicia de la Nación, 2013)

El debido proceso es un derecho fundamental, subjetivo y público que genera expectativas de acción u omisión a cargo del Estado en favor del individuo y que buscan limitar el quehacer de las autoridades en relación con su actuación de frente al ciudadano. Este derecho fundamental contiene, además, un conjunto de garantías, principios y derechos procesales, que tienen los gobernados cuyo significado es que la función de los servidores públicos no se asume como decisoria para establecer restricciones de libertad o acciones de molestia, sino por el contrario que dichos actos deberán ajustarse a los procedimientos que garantizan dichos principios.

Entendido el debido proceso como un derecho fundamental, guarda una íntima relación con otros derechos fundamentales, entre los que podemos considerar el de ocurrir a los tribunales en demanda de justicia y actuar en estos tribunales a fin de que sean tutelados nuestros intereses legítimos sin ninguna discriminación. También el derecho a una tutela jurisdiccional efectiva, que consiste en obtener de los órganos jurisdiccionales formas adecuadas de tutela efectiva, 


\section{http://revistainvestigacionacademicasinfrontera.com}

que aseguren la plena satisfacción de los derechos e intereses legítimos que se han hecho valer.

Los gobernados también tenemos el derecho a un juicio justo y público, de lo que se desprende, que nuestros asuntos sujetos a los tribunales deben ser tratados y discutidos públicamente, en un plazo razonable, frente un juez independiente e imparcial. El derecho fundamental de defensa de los gobernados, es aquel por el cual todos tenemos garantizado, en cualquier momento del proceso, el derecho inviolable de defendernos como partes iguales en el proceso, estando aseguradas también nuestras facultades de ser representados y defendidos por un abogado y de ser asistidos por peritos.

El derecho fundamental de prueba, tiene relación con el debido proceso legal, ya que a los gobernados se nos debe garantizar nuestra facultad de valernos de todos los medios de prueba legalmente admisibles y pertinentes para hacer valer nuestras pretensiones en juicio.

Sin embargo, el debido proceso es un derecho fundamental que se distingue de los otros derechos fundamentales contemplados en la Constitución porque, contiene como ya lo mencionamos en el párrafo anterior principios y derechos procesales, que constituyen una garantía de seguridad jurídica, al establecer que para poder privar a alguna persona, de cualquiera de los derechos contenidos en las leyes, deberá observarse un procedimiento. Sin embargo este carácter procesal del debido proceso, tiene una doble función, por una parte da origen a todos los procedimientos legales de carácter procesal ordinario, puestos a disposición de las personas para buscar la reparación, restitución o anulación de actos violatorios de sus derechos fundamentales y por la otra, da origen a un procedimiento constitucional que de igual manera busca, anular, privar de efectos o restituir en el goce de los derechos violentados (tanto substanciales como procesales) a través 


\section{http://revistainvestigacionacademicasinfrontera.com}

del juicio de amparo, y del cual el debido proceso constituye su condición de ejercicio.

A pesar de que el debido proceso es un derecho fundamental reconocido tanto en los Tratados Internacionales, como en diversas constituciones del mundo como es el caso de la mexicana, su contenido de carácter procesal ha provocado que aún existan diversos juristas que lo consideran más como un principio procesal o una garantía procesal que como un derecho fundamental. "El debido proceso presenta un carácter complejo. Bástese revisar que la doctrina y la jurisprudencia no se ponen de acuerdo de su esencia, ya que una parte importante plantea que se trata de una garantía otros de un derecho e incluso que se trata de un derecho al mismo tiempo garantía”. (Petit Guerra, 2011, pág. 3; Ferrajoli, Los fundamentos de los derechos fundamentales, 2005)

Fix Zamudio (2002) aclara que el debido proceso funciona como mecanismo de eficacia de la norma, "son numerosos los constitucionalistas que consideran que la verdadera garantía de los derechos de la persona humana consiste precisamente en su protección procesal, para lo cual es preciso distinguir entre los derechos del hombre y las garantías de tales derechos, que no son otra cosa que los medios procesales por conducto de los cuales es posible su realización y eficacia."

Concluyendo, el debido proceso como derecho fundamental, protege el manejo de reglas procesales tanto en el ámbito ordinario como constitucional para tomar decisiones que puedan justificarse jurídicamente, es decir, hay que analizar el derecho al debido proceso desde el punto de vista constitucional o sustancial y no desde el simplemente legal, lo que nos permitirá revisar su eficacia con respecto a la protección de la "sustancia" de la Constitución, es decir la protección efectiva de los derechos fundamentales. De esta manera los procedimientos específicos decididos de manera cotidiana y vueltos pautas de intervención por los funcionarios 
http://revistainvestigacionacademicasinfrontera.com

no pueden contradecir, sino guiarse, no solo por el respeto a la Constitución sino por la protección sustantiva de ésta.

\section{Las garantías de los derechos fundamentales, incluyendo el debido proceso}

En este apartado identificaremos los mecanismos legales que buscan garantizar el ejercicio de los derechos fundamentales, haciendo hincapié en las dos dimensiones que presenta el debido proceso como garantía ordinaria y garantía constitucional de derechos fundamentales, es decir, como opera como mecanismo para la protección de éstos. El 10 de junio de 2011 una reforma constitucional cambia el concepto a derechos humanos y crea un procedimiento hermenéutico de interpretación, separando la noción de derechos y garantías.(Carbonell, La reforma constitucional en materia de derechos humanos, 2012, pág. IX)

El debido proceso, tal como lo señala García Leal (2003), "presenta dos dimensiones: una procesal, que es aquella que engloba las instituciones jurídicas necesarias para obtener un proceso formalmente válido; y otra sustancial la cual se vincula directamente con el principio de razonabilidad y proporcionalidad de los actos de poder, y por tanto, determina la prohibición de cualquier decisión arbitraria." (García Leal, 2003)

Con respecto a la aparición de estas dos dimensiones que presenta el debido proceso, en un primer momento surge, la dimensión adjetiva o procesal que consiste en la exigencia de que las leyes y los actos de autoridad requieren para su validez, haber sido promulgados por órganos competentes y bajo los procedimientos establecidos para ello, (reserva de ley). ${ }^{3}$ García Lara, citando a Ambrosio (2000),

\footnotetext{
${ }^{3}$ Los antecedentes de esta etapa de la garantía del debido proceso se remontan a la Carta Magna inglesa de 1215, en la que el rey Juan Sin Tierra, otorga a los nobles ingleses entre otras garantías la del debido proceso.
} 


\section{http://revistainvestigacionacademicasinfrontera.com}

señala que en "esta primera etapa no se hizo aun cuestión constitucional de cuáles fueran los procedimientos preestablecidos o preestablecibles en cuanto a su contenido, sino sólo en cuanto a la imperatividad de su existencia y a que estuvieran prefijados por ley formal."(García Leal, 2003, pág. 2)

Esta dimensión adjetiva se extiende al debido proceso constitucional según , son explica esta misma autora, debido a las limitantes del principio de legalidad en el debido proceso, derivadas de su carácter meramente formal, este se extendió al llamado debido proceso constitucional, en el cual el proceso, además de ser regulado por la ley y reservado a esta, debe también en su mismo contenido, garantiza todos aquellos derechos y principios surgidos para la protección de las personas, ante el silencio, el error o la arbitrariedad y no solo en la aplicación del derecho, si también en la actuación del legislador, entendiéndose de esta forma, que la expresión de la Magna Chartalaw of thelandse, ${ }^{4}$ está referida a todo el sistema de las garantías -todavía sólo procesales o instrumentales- implicadas en la legalidad constitucional, mismo que es el concepto actual de la garantía constitucional del debido proceso. (García Leal, 2003, pág. 3)

En cuanto a la dimensión sustantiva, el gran aporte al constitucionalismo por parte de la tradición jurisprudencial norteamericana, lo constituye la extensión del debido proceso, a lo que ellos llamaron el "debido proceso sustantivo o sustancial" que no es otra cosa, nos dice García Leal (2003), que la exigencia de la aplicación del principio de razonabilidad entendiendo esto como el hecho de que las leyes, otras normas o actos públicos o privados, tengan como requisito de validez el ajustarse no solo a las normas o preceptos de la constitución, sino también al

\footnotetext{
4"Ningún hombre libre deberá ser arrestado, o detenido en prisión, o desprovisto de su propiedad, o de ninguna forma molestado; y no iremos en su busca, ni enviaremos por él, salvo por el juzgamiento legal de sus pares y por la ley de la nación".
} 


\section{http://revistainvestigacionacademicasinfrontera.com}

sentido de justicia contenido en ella, lo que implica necesariamente el acatamiento de exigencias fundamentales de equidad, proporcionalidad y razonabilidad.

En resumen, el concepto del debido proceso, a partir de la Carta Magna, pero muy especialmente en la jurisprudencia constitucional de los Estados Unidos, se ha desarrollado en los tres grandes sentidos descritos: a) el del debido proceso legal, adjetivo formal, entendido como reserva de ley y conformidad con ella en la materia procesal; b)el del debido proceso constitucional o debido proceso a secas, como procedimiento judicial justo, todavía adjetivo o formal procesal; y c) el del debido proceso sustantivo o principio de razonabilidad, entendido como la concordancia de todas las leyes y normas de cualquier categoría o contenido y de los actos de autoridades públicas con las normas, principios y valores del Derecho de la Constitución.(García Leal, 2003, pág. 4)

De igual forma, para Bustamante Alarcón, (2000) el proceso es una garantía en tanto lo concibe como el mecanismo protector no sólo de los derechos fundamentales sino también de ordenamiento jurídico en su conjunto. Haciendo también la distinción entre proceso y procedimiento, entendiendo el proceso como el mecanismo de solución de conflictos que se someten a la decisión de un órgano jurisdiccional; y el procedimiento como "...el conjunto de normas o reglas que regulan la actividad, participación, facultades y deberes de los sujetos procesales, así como la forma de los actos procesales; de tal suerte que bien puede existir procedimiento sin proceso, pero no proceso sin procedimiento."

Ese mecanismo protector de los derechos fundamentales y del ordenamiento jurídico en su conjunto no es otro que el proceso. De manera muy general podemos decir que éste es aquel mecanismo de composición o prevención de conflictos por medio del cual las partes en disputa someten su pretensión o sus 


\section{http://revistainvestigacionacademicasinfrontera.com}

intereses contrapuestos a la decisión de un tercero. Si este tercero es un órgano jurisdiccional estaremos ante un proceso propiamente dicho (interno o internacional), y si no lo es, ante un simple procedimiento (administrativo, arbitral, militar, e incluso político o particular). (Bustamante Alarcón, El derecho fundamental a un derecho justo llamado también debido proceso, 2000, pág. 68)

Para Lorca Navarrete, (2003)el proceso como garantía ordinaria, es superior a la acción, a la jurisdicción y a las formas de procedimiento, ya que el proceso representa la protección sustantiva de los derechos constitucionales y legales, ya que a través del proceso se garantiza a todos el derecho de accionar para el respeto y el amparo de los derechos consagrados en la Constitución.

$\mathrm{Ni}$ el concepto de acción, ni el de jurisdicción, ni menos aún las formas del procedimiento, pueden competir con el proceso como garantía ordinaria de aplicación del compromiso constitucional consistente en amparar, en el tráfico de bienes litigiosos los derechos que la Constitución Española reconoce a todos los ciudadanos. $Y$ si bien la posibilidad de accionar se atribuye a todos en condiciones de igualdad, y se justifica en un vínculo de medio a fin con la tutela sustantiva que oferta el proceso; lo determinante es aludir a una efectividad sustantiva de la posibilidad constitucional de accionar, que es garantizada a todos, a través del proceso".(Lorca Navarrete, 2003, pág. 247)

De igual forma para García Leal (2003), el debido proceso es una realidad sustantiva que va más allá de su concepción instrumentalista que implica la puesta en práctica de las garantías contenidas en las leyes procesales secundarias derivadas de la Constitución, por lo cual dicho proceso conlleva la posibilidad de actuación procesal en un plano de igualdad, ante los órganos jurisdiccionales, teniendo ambas partes la posibilidad de actuar y contradecir, asegurando, de esta forma, la proporcionalidad en su actuación. 


\section{http://revistainvestigacionacademicasinfrontera.com}

Este garantismo supone la conceptualización del proceso como realidad sustantiva ajena a su caracterización instrumental; implica la puesta en práctica de las garantías contenidas en las leyes procesales plenamente comprometidas con la realidad Constitucional aquí y ahora. Es incuestionable que para conseguir una justicia saludable, plena de equidad, abarcadora de las perspectivas de toda la sociedad y del propio Estado Democrático, como lo reclama esta época, se exige la confiabilidad de las partes en su ejecución legal, garantista e independiente, con proporcionalidad e iguales posibilidades de actuar y contradecir ante un órgano jurisdiccional imparcial.(García Leal, 2003, pág. 5)

El debido proceso, es entonces, el conjunto de garantías procesales y procedimentales frente a las cuales las autoridades se ven limitadas en su actuación al momento de restringir los derechos fundamentales de las personas, así, el derecho a conocer la acusación en su contra, el derecho a un juez imparcial, a gozar de un tiempo para preparar adecuadamente su defensa, a defenderse personalmente o por conducto de su abogado, a ofrecer y desahogar toda clase de pruebas, constituyen, entre otros, los requisitos que la autoridad está obligada a observar al momento de interpretar y aplicar las leyes, en el caso de las autoridades judiciales y administrativas, y en el caso de poder legislativo, la limitación consiste en no afectar en la creación de leyes los contenidos de las normas constitucionales, pero principalmente a orientar la creación de estas leyes a un sentido de justicia.

En este sentido, las normas que regulan el proceso legal, contienen entonces, un conjunto de actuaciones que se encuentran coordinadas, las cuales buscan seguirse a partir de normas establecidas y que se utilizan para la protección de las personas, sus bienes y derechos, tenemos así, una serie de actos que realizan las partes ante una autoridad jurisdiccional para resolver un conflicto jurídico suscitado entre las primeras, y para que estos actos tengan eficacia jurídica, deben realizarse de acuerdo, no solo a los procedimientos preestablecidos, sino 
http://revistainvestigacionacademicasinfrontera.com

buscando además, el desarrollo de un juicio justo, un fallo justo y razonable de acuerdo a los principios de justicia contenidos en la constitución.

Es pertinente señalar, que los procesalistas de viejo cuño han abordado el análisis del proceso y del procedimiento como derechos no como garantías, sin embargo actualmente el estudio del derecho procesal se empieza a realizar desde su carácter de garantía, tal y como lo vimos en los procesalistas citados en este apartado.

\section{La garantía sustantiva de los derechos fundamentales: el debido proceso constitucional}

Como ya vimos, el debido proceso contiene las dos dimensiones señaladas por García Leal, una procesal y otra sustancial. En la primera de ellas se encuentran todas las instituciones jurídicas que dan forma a un proceso formalmente valido 0 legal, como son la existencia de un juez natural, el derecho a la defensa, la cosa juzgada, el derecho a probar, etc. Mientras que la dimensión sustancial está vinculada directamente con la exigencia de aplicación del principio de razonabilidad y proporcionalidad en la emisión y realización de los actos de poder, lo que implica la prohibición de cualquier decisión arbitraria, emitida dentro o fuera de un proceso o procedimiento formalmente valido.

En este apartado revisaremos algunas conceptualizaciones en la doctrina, en relación al debido proceso constitucional o protección sustantiva de los derechos fundamentales.

Si bien es cierto el debido proceso nace en el ámbito penal, es así como en la materia penal existen las garantías penales y procesales. En lo relativo al proceso, se corresponden con las garantías procesales y orgánicas: el principio de contradicción, la paridad entre acusación y defensa, la separación rígida de juez y 


\section{http://revistainvestigacionacademicasinfrontera.com}

acusación, la presunción de inocencia, la carga de la prueba para el que acusa, la oralidad y la publicidad del juicio, la independencia interna y externa de la magistratura y el principio de juez natural. (Ferrajoli 2003)

Efectivamente en los tiempos modernos el debido proceso no se limita a ser una garantía procesal en materia penal, sino que su ámbito de validez se extiende a todos los actos de las autoridades sean administrativas o judiciales.

En la doctrina encontramos que el debido proceso es la actividad judicial o administrativa, encaminada a resolver pretensiones, la cual se desarrolla con arreglo y observancia de principios reunidos en el concepto de justicia, y particularizados en las normas de procedimiento. Es conveniente advertir el uso de la lógica del razonamiento ${ }^{5}$ en la toma de decisiones de los operadores jurídicos; así que la evaluación crítica de la aplicación de dichas decisiones, consiste en seguir las pautas de esos razonamientos.Gozaíni (2002) advierte que la exigencia de razonabilidad del principio del debido proceso garantiza otros principios de justicia, "La razonabilidad estableció límites a la potestad judicial, y constituyó un llamado o advertencia al Estado en el sentido de que deben ajustarse, no sólo a las normas o preceptos concretos de la Constitución, sino también al sentido de justicia contenido en ella, el cual implica, a su vez, el cumplimiento de exigencias fundamentales de equidad, proporcionalidad y razonabilidad”.(Gozaíni, 2002, pág. 62)

La idea de igualdad en el proceso le corresponde a la intervención del tercero imparcial. Gozaíni (2002) agrega al principio de igualdad, el de alegación y el económico de posibilidades de prueba fundada, "Que se dé

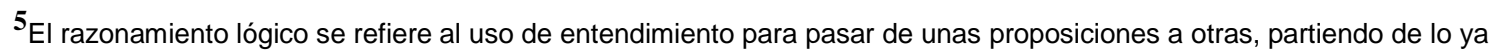
conocido o de lo que creemos conocer a lo desconocido o menos conocido. Se distingue entre razonamiento inductivo y razonamiento deductivo.
} 


\section{http://revistainvestigacionacademicasinfrontera.com}

plena observancia a las formalidades esenciales del procedimiento; por el cual se tiende a garantizar el principio de igualdad en el proceso (de oportunidades que cada parte tenga idénticas posibilidades de alegación y prueba, y económico que la mejor fortuna de uno no avasalle los derechos del otro); de tener una sentencia fundada; de poder recurrir contra ella, etcétera"

En un sentido el debido proceso se refiere a un principio de igualdad jurídica contenida en las leyes y en otro, a la sujeción del juez a proceder en tales circunstancias. Colombo Campbell (2004) advierte que el debido proceso tiene dos caras, una la de expectativa ciudadana y otra la de vinculación del juez"Una que nos muestra que es general y aplicable a todos los casos en que se emplee como forma de solución de conflictos y la otra referida al caso concreto en que el juez, en uso de su competencia específica, resuelve en un proceso determinado la materia sublite. Puede decirse que en este instante se suma a las garantías preestablecidas del debido proceso la actividad personal del juez que lo dirige y decide". (Colombo Campbell J. , 2004, pág. 162)

Autores como Gómez Lara (1974) advierten sobre la acepción garantista del debido proceso, entendido como un principio jurídico procesal o sustantivo según el cual toda persona tiene derecho a ciertas garantías mínimas, tendientes a asegurar un resultado justo y equitativo dentro del proceso, y a permitirle tener oportunidad de ser oído y hacer valer sus pretensiones frente al juez o una autoridad administrativa.

La dimensión material del debido proceso exige que todos los actos de poder, sean normas jurídicas, actos administrativos o resoluciones judiciales, inclusive, sean justos, es decir, que sean razonables y respetuosos de los valores superiores, de los derechos fundamentales y de los demás bienes jurídicos constitucionalmente protegidos, a tal punto que su inobservancia debe ser sancionada con la inaplicación de aquel acto o con su invalidez. De ese modo, un acto será considerado arbitrario, y por tanto lesivo del derecho 


\section{http://revistainvestigacionacademicasinfrontera.com}

fundamental a un debido proceso sustantivo, si no se sujeta a parámetros de razonabilidad; e es decir, si su fin no es lícito -en tanto vulnera un derecho o un bien jurídico de mayor jerarquía que el que pretenden protegerse y los medios para alcanzarlo no son proporcionales en tanto no respetan los principios de adecuación, necesidad y proporcionalidad en estricto.(Bustamante Alarcón, El derecho fundamental a un derecho justo llamado también debido proceso, 2000, pág. 78)

Así autores como Petit Guerra (2011, pág. 4) asumen que el debido proceso puede considerarse un derecho humano donde se emanan lo demás derechos "Entonces, en nuestro criterio el debido proceso se trata de un derecho humano como fundamental, por eso el intérprete que aplica normas procesales tiene que tener insumos suficientes para que en la construcción del derecho, haga argumentaciones a favor del hombre, nunca en contra".

El primer elemento de protección del debido proceso constitucional está en su fundamentación legal, que consiste en que el proceso tenga, a lo menos, bases normativas que posibiliten su eficacia; es decir, que la ley establezca enunciados claros sobre la estructura, función y desarrollo del proceso, en tanto que estos enunciados configuran los límites a que están sujetas las autoridades tanto administrativas como judiciales que lo ejecutan, fijando los derechos y obligaciones que tienen las partes que participan en el mismo. Colombo Campbell (2004) define el debido proceso constitucional por su función de eficacia para resolver conflictos y garantizar la eficacia del estado, "Para iniciar su examen, me referiré al concepto de "debido proceso" que, generalmente, se define como aquel que cumple integralmente la función constitucional de resolver conflictos de intereses de relevancia jurídica con efecto de cosa juzgada, protegiendo y resguardando, como su natural consecuencia, la organización del Estado, las garantías constitucionales 


\section{http://revistainvestigacionacademicasinfrontera.com}

y en definitiva la plena eficacia del derecho". (Colombo Campbell J. , 2004, pág. 158)

En sus múltiples contextos jurisdiccionales el debido proceso se concibe como límites a las decisiones de los jueces. Colombo Campbell (2004), al valorar la definición que hace, a su vez, Iñaki Esparza (1994), resalta su uso para satisfacer las expectativas de justicia de los individuos "En este sentido lo concibe como una válvula reguladora entre la libertad individual y las previsibles imposiciones de la autoridad, asumiendo la existencia de conflictos entre los ciudadanos y aquella, y encauzando la resolución de los mismos por medio del proceso". (Colombo Campbell J. , 2004, pág. 159)

En la teoría de las decisiones ${ }^{6}$ y en la posibilidad que conlleva para un individuo de argumentar reclamando la pérdida de derechos, el debido proceso mantiene la posibilidad de ulteriores litigios constitucionales a los procesos jurisdiccionales. Gozaíni atribuye a la posibilidad del alejamiento del procesalismo el ejercicio del derecho al debido proceso, "En este aspecto, el debido proceso se vislumbra como la necesidad de restaurar los derechos perdidos, donde no se pueden aplicar conceptos del procesalismo formal, porque la necesidad de reparación es más importante que el formalismo. Sería ni más ni menos que el derecho a tener un proceso sin resignaciones ni egoísmos adjetivos". (Gozaíni, 2002, pág. 67)

Así, el debido proceso constitucional, puede asumirse como la posibilidad de restañar las heridas que deja el uso de recursos del juicio ceñido a un procedimiento excesivamente rutinizado o formalista. Gozaíni (2002) sugiere que se pueda

\footnotetext{
6La teoría de la decisión es un estudio formal sobre la toma de decisiones. La toma de decisiones racionales en donde se utiliza la lógica y la estadística, se llama teoría preceptiva de la decisión, la complejidad de estos estudios, es mayor cuando en las decisiones participan varios individuos yno se conocen los resultados de diversas opciones por lo que las probabilidades de los distintos resultados son desconocidas.
} 


\section{http://revistainvestigacionacademicasinfrontera.com}

pretender remontar hacia el fondo de los deberes de la jurisdicción, "El debido proceso constitucional no se concreta en las afirmaciones de una ley, o en los preceptos de un código; se proyecta más que en los derechos, hacia los deberes jurisdiccionales que se han de preservar con la aspiración de conseguir un orden objetivo más justo". (Gozaíni, 2002, pág. 66) que necesariamente encuentra su fundamento en las constituciones.

En la doctrina jurídica se ha hecho hincapié en el carácter procesal del debido proceso, es decir se le ha tratado como una garantía procesal constitucional, dejando de lado su pertenencia al sistema de control de constitucionalidad, situación que consideramos ha generado su debilitamiento, dejándose de lado la utilización de otros mecanismos de este bloque de constitucionalidad, como el juicio político y la responsabilidad de los funcionarios, los cuales bien podrían ampliar los márgenes de protección de los derechos fundamentales, a partir de que no sólo se obligaría a las autoridades a nulificar sus actos violatorios de derechos o privarlos de efectos, (que es la consecuencia del derecho de amparo), sino que se les fincaría responsabilidad por sus actos contrarios a la obligación constitucional de respetar y hacer respetar la Constitución, lo cual podría ser el resultado de la aplicación de los procedimientos de juicio político y de responsabilidad oficial.

Ahora bien, Sarrazá Jimena(2008, pág. 312) considera que para: "La protección de los derechos fundamentales, asegurada por la constitución y desarrollada por la ley, corresponde, tanto al juez ordinario como al constitucional, pues tanto el uno como el otro están vinculados por esos derechos y sujetos a la aplicación de la Constitución. Así pues, no pueden separarse esos planos como si fueron compartimentos, estancos y encomendar la tutela de la Constitución a un juez y la de la ley a otro, pretendiendo que actúen de modo separado y sin ningún tipo de contacto. Todos, por el contrario, participan en el único sistema de garantía de 


\section{(Edición especial julio- diciembre 2016)}

\section{http://revistainvestigacionacademicasinfrontera.com}

Revista de Investigación

Académica sin Frontera ISSN: 2007-8870

derechos reconocidos por la norma fundamental. Por eso mismo, porque se trata de un sistema único, dentro de la unidad del ordenamiento jurídico, hace falta encomendar a alguien la última palabra. En materia de interpretación de la Constitución y, especialmente, en el ámbito de las garantías constitucionales, la última palabra la tiene en España el Tribunal Constitucional."(Sarrazá Jimena, 2008, págs. 312-377).

\section{Conclusiones}

El debido proceso dentro del nuevo paradigma neo constitucionalista busca asegurar o garantizar a las personas no solo un proceso legal, sino fundamentalmente un proceso justo, entendiendo por este, aquel que garantice que al final del mismo la o las personas afectadas recibirán la reparación o restitución en su caso de la afectación recibida, se busca entonces, que el debido proceso actué como una limitación efectiva a las facultades de molestia o privación de un bien jurídico que tiene una determinada autoridad judicial o administrativa, las cuales deberán acatar las formas jurídicas que conforman el debido proceso, a fin de que el acto de molestia no pueda llevarse a cabo, sino a condición de evitar la violentación de los derechos fundamentales, es decir, se pretende garantizar la legalidad y seguridad jurídica sustantiva, que deben estar presentes en todos los actos jurisdiccionales.

El debido proceso como derecho fundamental, en su núcleo integra las garantías mínimas a favor de las personas, que exigen; la existencia de una autoridad judicial imparcial; que esta autoridad dicte una resolución conforme a derecho, y que exista una autoridad jerárquicamente superior a la que dictó la sentencia o resolución, para confirmarla, revocarla o modificarla. 
Año 9. Núm. 24 (Edición especial julio- diciembre 2016)
Revista de Investigación

Académica sin Frontera ISSN: $2007-8870$

\section{http://revistainvestigacionacademicasinfrontera.com}

\section{Referencias}

Ferrajoli, L. (2005). Los fundamentos de los derechos fundamentales (segunda ed.). Madrid: Trotta.

Ferrajoli, L. (18 de Noviembre de 2007). Garantías. Recuperado el 11 de mayo de 2012, de Procesal Penal Word Press:

http://procesalpenal.wordpress.com/2007/11/18/garantías-artículo-de-luigiferrajoli

Ferrajoli, L. (s.f.). Garantías. Recuperado el 23 de 05 de 2015, de www.defensapublica.org.ar/.../Articulo_garantias_ferrajoli.doc

García Leal, L. (Diciembre de 2003). El debido proceso y la tutela judicial efectiva. Frónesis, 10(3), 1-7.

Petit Guerra, L. A. (13 de Enero de 2011). Debido proceso y su hermenéutica. Revista Internauta de Práctica Jurídica(26).

Suprema Corte de Justicia de la Nación. (2013). Las Garantías de Seguridad Jurídica. Colección de Garatntías Individuales. D.F.: Suprema Corte de Justicia de la Nación. 